\title{
Effect of Artificial Aging Temperature on Mechanical Properties of 6061 Aluminum Alloy
}

\author{
MUKESH KUMAR*, MUHAMMAD MOAZAM BALOCH*, MUHAMMAD ISHAQUE ABRO*, \\ SIKANDAR ALI MEMON* AND ALI DAD CHANDIO** \\ RECEIVED ON 16.01.2017 ACCEPTED ON 12.02.2018 \\ ABSTRACT
}

\begin{abstract}
Aluminum alloys have been attracted by several engineering sectors due to their excellent strengthweight ratio and corrosion resistant properties. These are categorized into 1, 2,3, 4, 5, 6, 7and 8xxx on the basis of alloying elements. Among these 6xxx series contains aluminum-magnesium-silicon as alloying elements and are widely used in extruded products and automotive body panels. The major advantages of these alloys are good corrosion resistance, medium strength, low cost, age hardening response no yield point phenomenon and Ludering. 6 xxx series alloys generally have lower formability than other aluminum alloys which restrict their utilization for wide applications. Keeping in view of the shortcomings in the set of mechanical properties of 6xxx series the efforts were made to improve the tensile strength and toughness properties through age hardening. In present study heat treatment cycles were studied for 6061 aluminum alloy. Three different age hardening temperatures 160, 200 and $240^{\circ} \mathrm{C}$ were selected. The obtained results showed that $17.26,7.69$, and $10.51 \%$ improvement in tensile strength, toughness and hardness respectively was achieved with solution treatment at $380^{\circ} \mathrm{C}$ followed by an aging $240^{\circ} \mathrm{C}$. Microstructural study revealed that substantial improvements in the mechanical properties of 6061 aluminum alloy under heat treatment were achieved due to precipitation of $\mathrm{Mg}_{2} \mathrm{Si}$ secondary phase.
\end{abstract}

Key Words: Aluminum Alloy 6061, Solution Treatment, Age Hardening, Microstructure, Mechanical Properties.

\section{INTRODUCTION}

1 luminum is very light and soft metal in periodic table. Due to light weight it is highly attracted by modern manufacturing technologies. Its mechanical properties can be enhanced through alloying. Aluminum alloys have been greatly appreciated and consumed by several engineering sectors including; aircrafts, automotive, buildings and marine etc due to their excellency in strength-weight ratio and corrosion resistant properties [1-2]. Table 1 shows the capability of aluminum to be alloyed with different metals and nonmetals. Depending on the type of alloying elements, aluminum can be utilized by various sectors. It is reported that worldwide $90 \%$ pipes and tubes are manufactured from 6xxx aluminum alloy. This type of aluminum alloy contains $\mathrm{Si}$ and $\mathrm{Mg}$ as a major alloying element. 6xxx aluminum alloys are heat treatable.

Authors E-Mail: (mukesh.kumar@faculty.muet.edu.pk, moazam.baloch@faculty.muet.edu.pk, ishaque.abro@faculty.muet.edu.pk, moazam.baloch@faculty.muet.edu.pk, alidad_24@hotmail.com)

* Department of Metallurgy \& Materials Engineering, Mehran University of Engineering \& Technology, Jamshoro, Pakistan. ** Department of Metallurgical Engineering, NED University of Engineering \& Technology, Karachi, Pakistan.

This is an open access article published by Mehran University Research Journal of Engineering and Technology, Jamshoro under the CC by 4.0 International License. 
Literature pertaining to 6061 aluminum alloy, hereinafter referred to as 6061-AA, reveals that heat treatments efforts are ongoing to improve the tensile strength in order to make it more efficient and reliable [3-4]. Many others have noted the challenges to improve the strength without compromising on its toughness value through age hardening treatment.

Age hardening of aluminum alloys include two major steps; solution treatment and artificial aging. Solution treatment involves heating of materials above its critical temperatures, soaking for a particular time and rapid quenching. Quenching is carried out to trap the dissolved constituents in solid solution [4-5]. Whereas, artificial aging means re-heating of the solution treated samples in the range of $175-420^{\circ} \mathrm{C}$ for various time periods in order to precipitate the secondary phase [6]. Previous research revealed that the selection of appropriate temperature and time in artificial aging is the critical step. Substantial improvement in the mechanical properties of the $6 \mathrm{xxx}$ series aluminum alloy has been observed by most of the researchers after aging in the range of $180-260^{\circ} \mathrm{C}$. The sole reason behind the dramatic change in the properties

TABLE 1. ALUMINUM ALLOY SERIES AND THEIR ALLOYING ELEMENTS

\begin{tabular}{|c|c|}
\hline Alloy Series & Principal Alloying Element \\
\hline $1 \times x x$ & Pure Aluminum \\
\hline $2 \times x x$ & Copper \\
\hline $3 \times x x$ & Manganese \\
\hline $4 x x x$ & Silicon \\
\hline $5 x x x$ & Magnesium \\
\hline $6 x x x$ & Magnesium and Silicon \\
\hline $7 x x x$ & Zinc \\
\hline $8 x x x$ & Other Element \\
\hline
\end{tabular}

is the formation of secondary stable phases. From previous work, it is noted that the formation of $\mathrm{Mg}_{2} \mathrm{Si}$ (stable $\beta$ phase) involves transformation of many metastable phases both coherent and semi-coherent when 6xxx aluminum alloys are artificially age-hardened in the range of 180 and $260^{\circ} \mathrm{C}[7-10]$.

Although much efforts have been paid to improve tensile and hardness properties through age hardening, however little work is reported to evaluate the effect of secondary micro phases on the toughness and bending property. Due to diverse applicability it is important to design such heat treatment cycle through which it could be possible to improve mechanical properties. Efforts were made to optimize the aging temperature to obtain set of better strength and higher toughness values of 6061-AA.

\section{MATERIALS AND METHOD}

Aluminum alloy(6061) was purchased from the local market (Karachi). Chemical composition of the aluminum alloy was determined by using optical emission spark spectrometer (Model: Bruker Q2-ION). The obtained average composition of 6061-AA is given in Table 2, which indicates that $\mathrm{Mg}$ and $\mathrm{Si}$ are the major alloying elements. Before heat treatment, standard specimens of tensile, toughness and bend tests were prepared by performing machining operation as per sample specifications as shown in Fig. 1. Afterward, the samples were heat treated (solution treatment and age hardening) in a muffle furnace, as per designed heat treatment cycles of Fig. 2. Later on tests were performed in order to evaluate mechanical properties.

TABLE 2. CHEMICAL COMPOSITION OF 6061-AA

\begin{tabular}{|c|c|c|c|c|c|c|c|c|c|}
\hline Elements & $\mathrm{Si}$ & $\mathrm{Cr}$ & $\mathrm{Cu}$ & $\mathrm{Fe}$ & $\mathrm{Mg}$ & $\mathrm{Mn}$ & $\mathrm{Ti}$ & $\mathrm{Zn}$ & $\mathrm{Al}$ \\
\hline Percentage & 0.54 & 0.38 & 0.005 & 0.64 & 1 & 0.39 & 0.005 & 0.03 & $\mathrm{Rest}$ \\
\hline
\end{tabular}

Mehran University Research Journal of Engineering \& Technology, Volume 38, No. 1, January, 2019 [p-ISSN: 0254-7821, e-ISSN: 2413-7219] 
For microstructural investigation, samples were ground and polished using emery paper of $800,1000,1200$ grid sizes and finally etched in solution containing
$25 \mathrm{ml}$ of methanol, $25 \mathrm{ml}$ of nitric acid, $25 \mathrm{ml}$ of hydrochloric acid and one drop of hydrofluoric acid [11-14].
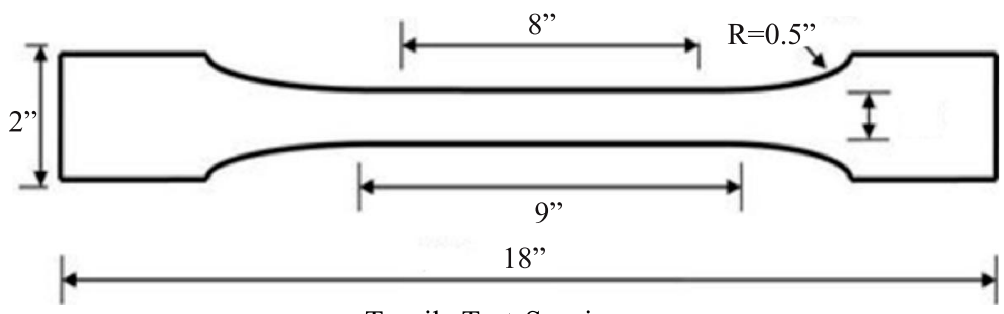

Tensile Test Specimen
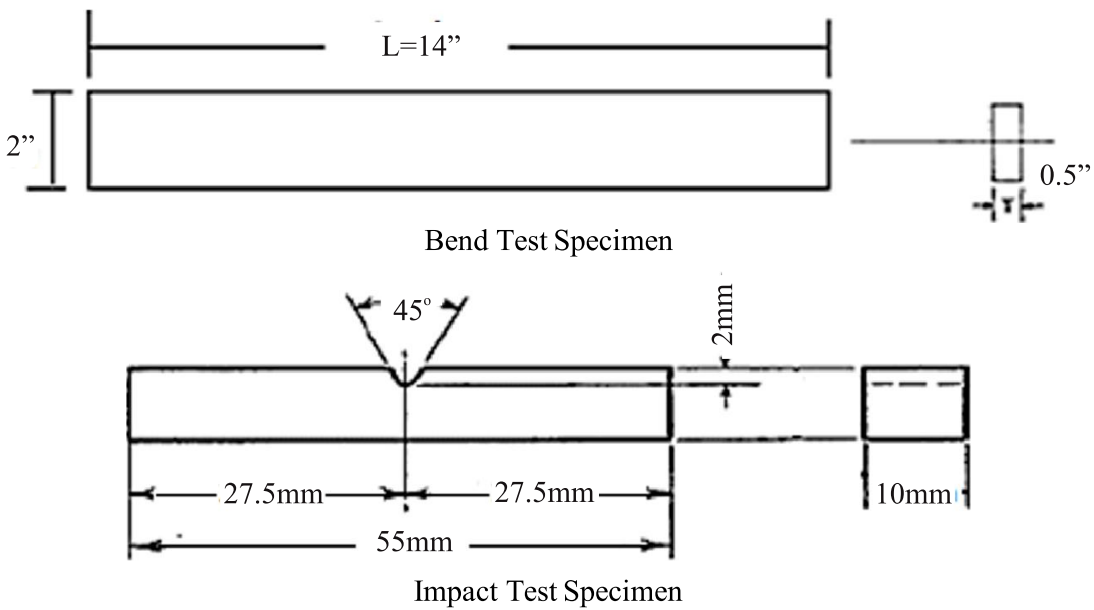

FIG. 1. SAMPLE SPECIFICATIONS FOR TENSILE, IMPACT AND BEND TEST [15]

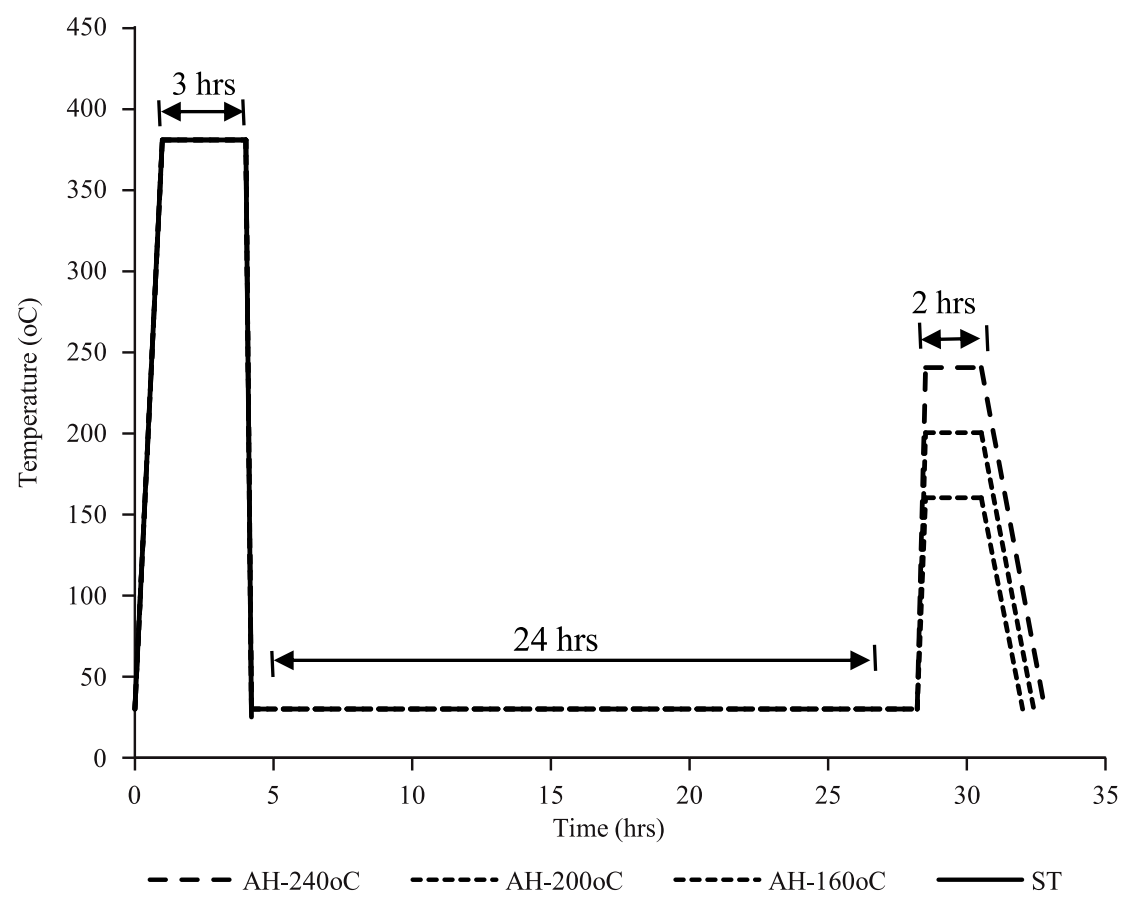

FIG. 2. HEAT TREATMENT CYCLES

Mehran University Research Journal of Engineering \& Technology, Volume 38, No. 1, January, 2019 [p-ISSN: 0254-7821, e-ISSN: 2413-7219] 


\section{RESULTS AND DISCUSSION}

Tensile test results of 6061-AA are shown in Fig. 3 which indicate significant alteration in the UTS (Ultimate Tensile Strength) and PE (Percent Elongation) achieved at different conditions. It can be seen in Fig. 3 that when 6061-AA with 157 M. Pascal UTS was age hardened at 160,200 and $240^{\circ} \mathrm{C}$, its UTS was increased to 172,177 , and 184 M Pascal respectively. In contrast, the percent elongation of 6061- AA samples was decreased from 38$33 \%$. In addition, hardness and toughness results shown in Fig. 4, also indicate that with increasing the age hardening temperature the appreciable improvement in these properties were resulted. The obtained results showed that solution treatment followed by aging at higher temperature resulted high set of mechanical properties as demanded by end users of this alloy. The improvements in the tensile, hardness, and toughness can be explained by taking into account the microstructure changes encountered during the age hardening process. It was also noted from free bend test that there was no significant effect on bending property. Minor surface roughness was observed on sample hardened at $240^{\circ} \mathrm{C}$ but according to the standard it was tolerable. The obtained tensile strength is compared with published results. It is noticed that the obtained maximum tensile strength was typically greater than published research [15-16]. It was also validated that age hardened 6061 aluminum alloy was more strengthen as compared to heat treated Al-Ti alloys.

Detailed microstructural examination reported elsewhere, revealed that by solution treatment at $380^{\circ} \mathrm{C}$ all the alloying elements were dissolved in aluminum matrix [1718]. When the solution treated samples were aged at different temperatures the precipitation process of

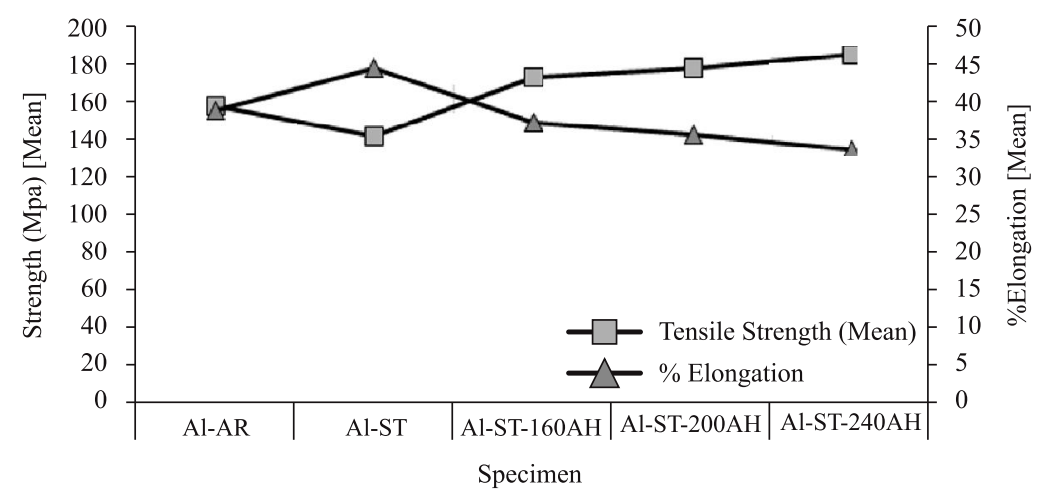

FIG. 3. RESULTS OF TENSILE STRENGTH (MPA) AND PERCENTAGE ELONGATION

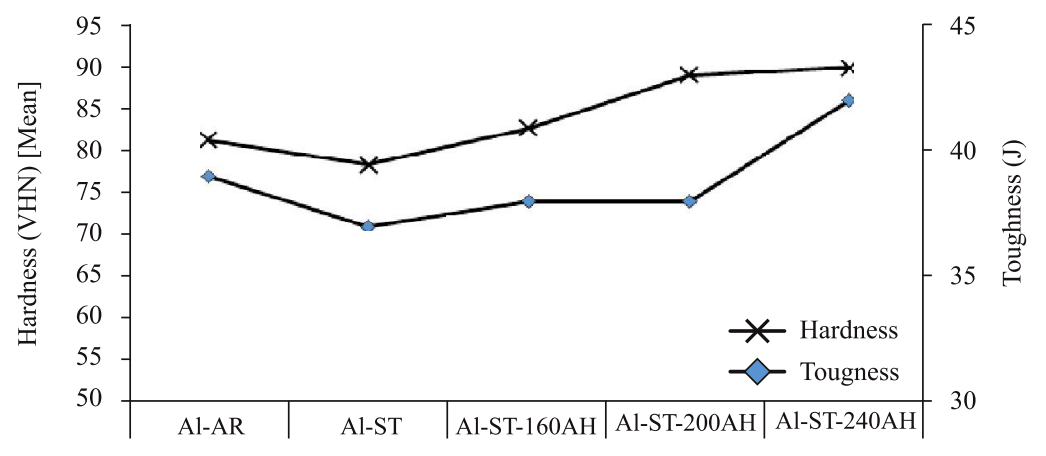

FIG. 4. RESULTS OF TOUGHNESS AND HARDNESS

Mehran University Research Journal of Engineering \& Technology, Volume 38, No. 1, January, 2019 [p-ISSN: 0254-7821, e-ISSN: 2413-7219] 
secondary carbides was started according to the sequence of SSP $\rightarrow \mathrm{GPZ} \rightarrow \beta$ " $\rightarrow \beta$ ' $\rightarrow \beta$. Where, SSP means supersaturated phase, GPZ (Guinier Prestone Zone), and $\beta$ ", $\beta$ ' and $\beta$ indicate the birth, childhood and mature position of secondary $\mathrm{Mg}_{2} \mathrm{Si}$, respectively. In our study it was noted that the initiation and growth of $\mathrm{Mg}_{2} \mathrm{Si}$ are the function of the aging temperature. We noted that at $160^{\circ} \mathrm{C}$ aging temperature the SSP entered into GPZ which can be seen in Fig. 5(b). When the aging temperature was increased to 200 and $240^{\circ} \mathrm{C}$ the precipitates of secondary phase $\mathrm{Mg}_{2} \mathrm{Si}$ were developed that can be seen in Fig. 5(cd).

It is interesting to note that by the solution treatment the UTS, toughness and hardness of the samples was decreased as compared to received samples. The sole reason of this decrease in the properties noted from microstructural investigation was the dissolution of the alloying element in the matrix of aluminum. When the samples were age hardened at lower and higher temperatures the precipitation of secondary carbide $\mathrm{Mg}_{2} \mathrm{Si}$ was commenced due to which the improvement in the UTS, toughness and hardness was observed. More interestingly from the increasing trend of the UTS, toughness and hardness can be seen from Figs. 3-4. Results of the sequence of precipitation can be confirmed and validated. The present experimental study recommended that high temperature solution treatment for various soaking time should be carried out to evaluate the effect of solutionizing temperature on mechanical properties of 6061-AA.

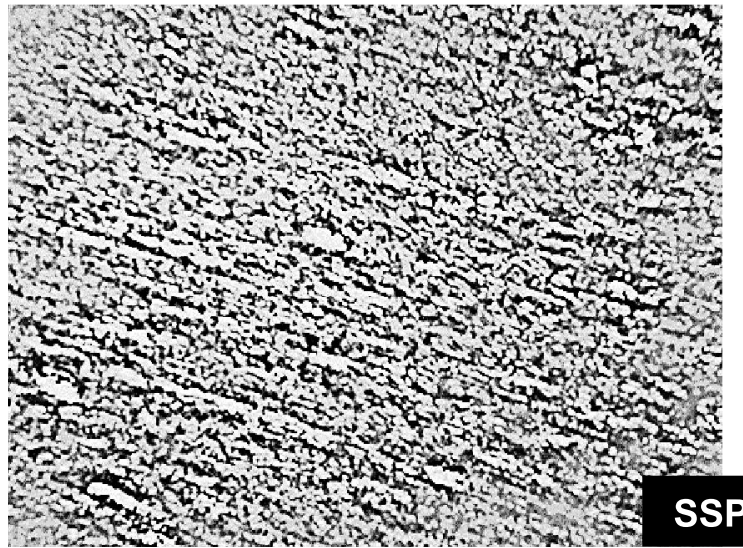

(a) SOLUTION TREATMENT AT $380^{\circ} \mathrm{C}$

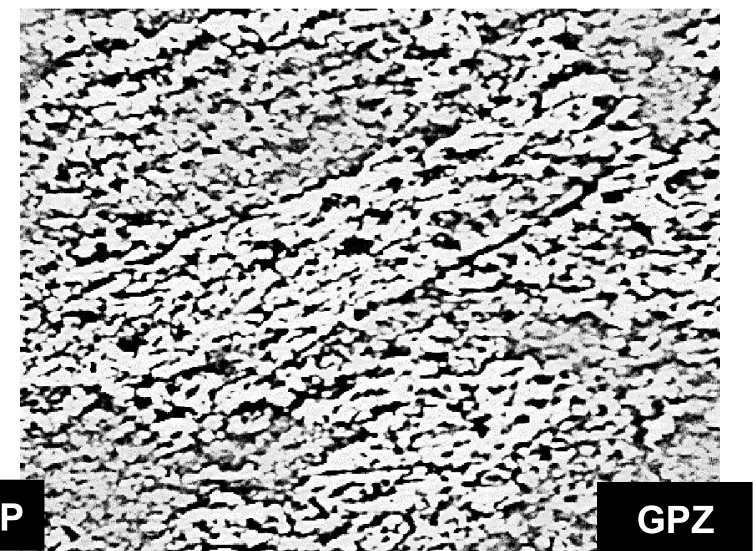

(b) AGE HARDENING AT $160^{\circ} \mathrm{C}$

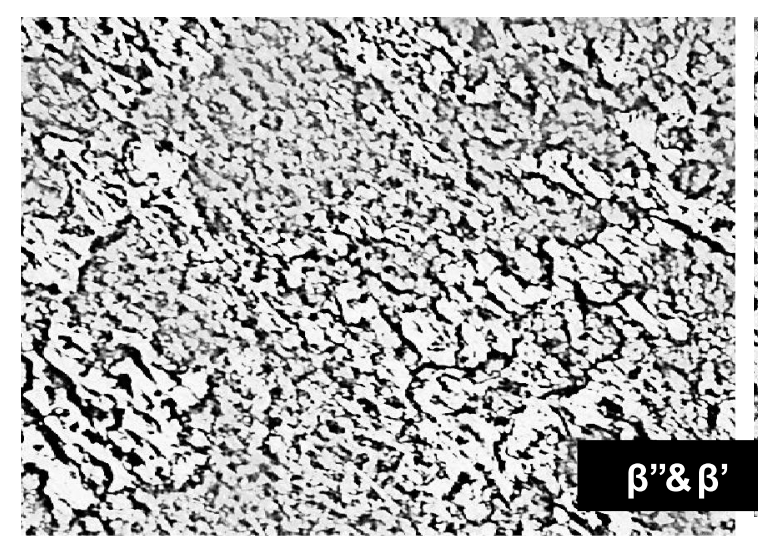

(c) AGE HARDENING AT $200^{\circ} \mathrm{C}$

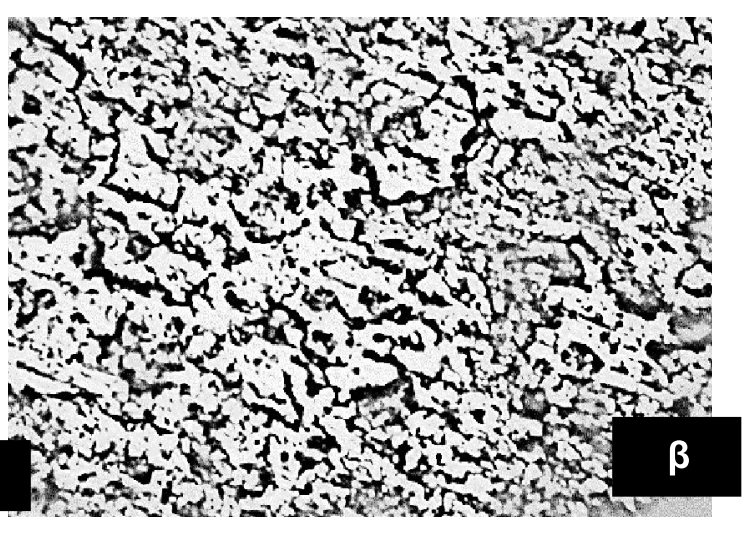

(d) AGE HARDENING AT $240^{\circ} \mathrm{C}$

FIG. 5. MICROSTRUCTURE OF ALUMINUM ALLOY AFTER 


\section{CONCLUSION}

It is concluded that the aging of solution treated samples has a positive effect on mechanical properties. Aging at the higher temperature increases the nucleation rate of $\mathrm{Mg}_{2} \mathrm{Si}$ precipitates. It can also be concluded that maximum hardness, strength and percentage elongation and toughness is attained at $240^{\circ} \mathrm{C}$ due to intermediate grain size and evenly distribution of $\mathrm{Mg}_{2} \mathrm{Si}$ precipitates.

\section{ACKNOWLEDGEMENT}

The authors greatly acknowledge the Department of Metallurgy \& Materials Engineering, Mehran University of Engineering \& Technology, Jamshoro, Pakistan, for their cooperation in providing the lab facilities for conducting the experimental work. Also highly acknowledge Mr. Jahanzaib Mahar, for providing us mechanical testing facilities at Huffaz Seamless Pipes Ltd. Authors also wish to thank the Organizing Committee of $2^{\text {nd }}$ National Conference on Metallurgy and Materials, for providing the platform for oral presentation and publishing the paper in Mehran University Research Journal of Engineering \& Technology.

\section{REFERENCES}

[1] Hao, Z., Paul, R., and Yuri, E., "Effect of Alloy Composition and Heat Treatment on Mechanical Performance of 6xxx Aluminum Alloys", Transactions of Nonferrous Metal Society of China, Volume 24, pp. 2174-2178, 2014.

[2] Ozturk, F., Sisman, A., Toros, S., Kilic, S., and Picu, R.C., "Influence of Aging Treatment on Mechanical Properties of 6061 Aluminum Alloy", Materials and Design, Volume 31, pp. 972-975, 2010.

Lang, P.,Erwin, P-K., Ahmed, F., and Ernst, K., "Simulation of the Effect of Composition on the Precipitation in 6xxx Al Alloys During ContinuousHeating DSC", Journal of Alloys and Compounds, Volume 612, pp. 443-449, 2014

[4] Zoller, H., and Ried, A., "Metallurgical Aspects in Development of Al Mg Si Alloys with a Low Sensitivity to Quenching”, Z Metallkd, Volume 62, pp. 354-358, 2005 . Engineering Materials", John Wiley \& Sons, Lafayette College, New York, 1999.

6] Marioara, C.D., Nordmark, H., Anderson, S.J., and Holmestad, R., "Post â-phases and their influences on microstructure and hardness in 6xxx Al-Mg-Si alloys", Journal of Materials Science, Volume 46, pp. 471-478, 2006.

[7] Edwards, G.A., Stiller, K., Dunlop, G.L., and Couper, M.J., "The Precipitation Sequence in Al-Mg-Si Alloys", Acta Material, Volume 46, pp. 3898-3904, 1998.

[8] Marioara, C.D., Anderson, S.J., Jansen, J., and Zandbergen, H.W., "The Influence of Temperature and Storage Time at RT on Nucleation of the Beta Phase in a 6082 Al-Mg-Si Alloy", Acta Material, Volume 51, pp. 789-796, 2003.

[9] Yassar, S.R., "Field Transmission Electron Microscopy and Differential Scanning Calorimetry Studies on the Precipitation Sequence in an Al-Mg-Si Alloy: AA6022", Journal of Materials Research, Volume 20, pp. 2705-2711, 2005.

[10] Hand Book "Heat Treating", ASM International, Materials Park, pp. 841-879, 1991.

[11] Kulkarni, A.J., Krishnamurthy, K., Deshmukh, S.P., and Mishra, R.S., "Effect of Particle Size Distribution on Strength of Precipitation-Hardened Alloys", Journal of Materials Research, Volume 19, No. 9, 2004.

[12] Callister, W.D., "Material Science and Engineering", John Wiley and Sons, New York, 1997.

[13] Hosford, W.F., "Overview of Tensile Testing, Tensile Testing", ASM International, Materials Park, pp. 1-24, 1992.

[14] Bergsma, S.C., Kassner, M.E., Li, X., and Rosen, R.S., "The Quench Sensitivity of Hot Extruded 6061-T6 and 6069-T6 Aluminum Alloys", Proceedings of International Conference on Processing and Manufacturing of Advanced Materials, Session A-4, Las Vegas, Nev, USA, December, 2000.

[15] Kuhn, H., and Medlin, D., "ASM Handbook Mechanical Testing and Evaluation", ASM International, Ohio, USA, 2000 .

[16] Talabi, S.I., Adeosun, S.O., Alabi, AF., Aremu, I.N., and Abdulkareem, S.,"Effects of Heat Treatment on the Mechanical Properties of Al-4\% Ti Alloy", International Journal of Metals, 2013.

[17] Mansourinejad, M., and Mirzakhani, B., "Influence of Sequence of Cold Working and Aging Treatment on Mechanical Behaviour of 6061-AA", Transactions of Nonferrous Metals Society of China, Volume 22, No. 9 , pp. 2072-2079, 2012.

[18] Evren, T., and Bilgehan, O.,'Influence of Heat Treatment on the Mechanical Properties of AA6066 Alloy", Turkish Journal of Engineering \& Environmental Sciences, Volume 31, No. 1, pp. 53, 2007. 